Full length article

\title{
Multilayered membranes with tuned well arrays to be used as regenerative patches
}

\author{
Nádia I. Martins ${ }^{\text {a, b, }}$, Maria P. Sousa ${ }^{\mathrm{a}, \mathrm{b}, 2,1}$, Catarina A. Custódio ${ }^{\mathrm{a}, \mathrm{b}, 2}$, Vânia C. Pinto ${ }^{\mathrm{c}}$, Paulo J. Sousa ${ }^{\mathrm{c}}$, \\ Graça Minas ${ }^{\mathrm{c}}$, Franck Cleymand ${ }^{\mathrm{d}, \mathrm{e}}$, João F. Mano ${ }^{\mathrm{a}, \mathrm{b}, *}$ \\ a $3 B$ 's Research Group - Biomaterials, Biodegradables and Biomimetics, University of Minho, Headquarters of the European Institute of Excellence on Tissue Engineering and \\ Regenerative Medicine, AvePark, 4806-909 Taipas, Guimarães, Portugal \\ ${ }^{\mathrm{b}}$ ICVS/3B's - PT Government Associate Laboratory, Braga/Guimarães, Portugal \\ ${ }^{c}$ Microelectromechanical Systems Research Unit (CMEMS-UMinho), University of Minho, Campus de Azurém, 4800-058 Guimarães, Portugal \\ d Ecole des Mines de Nancy, Campus Artem, CS 14234, 54042 Nancy Cedex, France \\ e Jean Lamour Institute, UMR 7198 CNRS-Lorraine University, Parc de Saurupt CS50840, 54011 Nancy Cedex, France
}

\section{A R T I C L E IN F O}

\section{Article history:}

Received 9 December 2016

Received in revised form 13 April 2017

Accepted 19 April 2017

Available online $\mathrm{xxx}$

Keywords:

Quasi-3D

Layer-by-layer

Polyelectrolyte multilayers

Tissue engineering

Patterning

\begin{abstract}
A B S T R A C T
Membranes have been explored as patches in tissue repair and regeneration, most of them presenting a fla geometry or a patterned texture at the nano/micrometer scale. Herein, a new concept of a flexible membrane featuring well arrays forming pore-like environments to accommodate cell culture is proposed. The processing of such membranes using polysaccharides is based on the production of multilayers using the layer-by-layer methodology over a patterned PDMS substrate. The detached multilayered membrane exhibits a layer of open pores at one side and a total thickness of $38 \pm 2.2 \mu \mathrm{m}$. The photolithography technology used to produce the molds allows obtaining wells on the final membranes with a tuned shape and micro-scale precision. The influence of post-processing procedures over chitosan/alginate films with 100 double layers, including crosslinking with genipin or fibronectin immobilization, on the adhesion and proliferation of human osteoblast-like cells is also investigated. The results suggest that the presence of patterned wells affects positively cell adhesion, morphology and proliferation. In particular, it is seen that cells colonized preferentially the well regions.

The geometrical features with micro to sub-millimeter patterned wells, together with the nano-scale organization of the polymeric components along the thickness of the film will allow to engineer highly versatile multilayered membranes exhibiting a pore-like microstructure in just one of the sides, that could be adaptable in the regeneration of multiple tissues.

Statement of Significance

Flexible multilayered membranes containing multiple micro-reservoirs are found as potential regenerative patches. Layer-by-layer ( $\mathrm{LbL}$ ) methodology over a featured PDMS substrate is used to produce patterned membranes, composed only by natural-based polymers, that can be easily detached from the PDMS substrate. The combination of nano-scale control of the polymeric organization along the thickness of the chitosan/alginate (CHT/ALG) membranes, provided by LbL, together with the geometrical micro-scale features of the patterned membranes offers a uniqueness system that allows cells to colonize 3-dimensionally. This study provides a promising strategy to control cellular spatial organization that can face the region of the tissue to regenerate.
\end{abstract}

(C) 2016 Published by Elsevier Ltd.

\section{Introduction}

Tissue engineering procedures have often employed porous scaffolds, as three-dimensional supports for initial cell attachment and subsequent tissue formation both in vitro and in vivo [1]. Many techniques have been proposed to fabricate such structures, where pore

\footnotetext{
* Corresponding author at: CICECO - Aveiro Institute of Materials, Department of Chemistry, University of Aveiro, 3810-193 Aveiro, Portugal.

Email address: jmano@ua.pt (J.F. Mano)

${ }^{1}$ Both authors contributed equally to this work.

2 Present address: CICECO - Aveiro Institute of Materials, Department of Chemistry, University of Aveiro, 3810-193 Aveiro, Portugal
}

size and porosity could be easily controlled [1,2]. For some applications like wound-dressing [3,4], cardiac [5], cornea [6], periosteum $[7,8]$, periodontal $[9,10]$ and nerve regeneration [11], 2-dimensional (2D)-like devices have been explored as supportive structures for cell attachment, growth and differentiation. In flat membranes, cells do not recognize the same pseudo 3-dimensional (3D) environment as in conventional porous 3D scaffolds [12]. It is well known that cell behavior is highly dependent on the topography of the scaffolds, including mechanical properties [13], roughness [14], width and depth of the substrate pattern [15], as well as the geometry of the exposed sites for cellular adhesion [16-18]. In order to provide geometrical features, the surface of 2D substrata has been patterned with topographic motifs, usually exploring pillars and grooves textures at the nano and 
sub-micro scale-level [19-22]. The integrin-mediated mechanotransduction takes place through many intracellular molecular pathways that result to changes in the biological outcomes through mechanical forces [23]. The development of patterned scaffolds that can tailor cell-substrate interactions [24-26] will provide and stimulate specific biological recognition pathways to control the cytoskeletal organization of the cells $[26,27]$.

Across the few studies $[28,29]$ that have explored micro-sized patterns in 2D substrates, none have investigated the effect of membranes with tuned well arrays forming pore-like environments in cell function. We hypothesize that the existence of such structures could help cells to organize adequately towards a new tissue formation.

It is widely known that the pore size of 3D scaffolds influences cellular behavior. For example, in collagen scaffolds with pores diameter ranging between $85 \mu \mathrm{m}$ and $325 \mu \mathrm{m}$, more adhered cells were observed in the structures with the biggest pores size [30]. Although several studies were already reported about the pore size effect [30-33], significant less investigation has been addressing the effect of geometry and curvature on cellular adhesion and proliferation. Still, recent literature [34-36] has been reporting the influence of scaffolds surface curvature on the kinetics of tissue formation; in vitro and in vivo studies comparing tissue growth in natural bone structures and in hydroxyapatite scaffolds showed that the tissue formation occurs preferentially on the concave areas of the scaffolds [35].

Herein, we propose a new concept of quasi-3D freestanding membranes that exhibit an open pore layered organization in one side of the membrane, with a well-defined geometrical feature to control cellular behavior. For the proof of concept, we patterned wells with $500 \mu \mathrm{m}$ of diameter and about $15 \mu \mathrm{m}$ of depth in nanostructured multilayered films. We explored the possibility of controlling cell function by tuning the geometry of the pores, which is not straightforward in 3D scaffolds. The strategy herein proposed offers versatile possibilities for adapting the membranes morphology and pattern to the desired application. To prepare such kind of membranes made of non-meltable natural-based materials, solution-based processing techniques must be preferentially used. Solvent casting is a widely used method to prepare films, but it might not be adequate to process the envisaged patterned membranes, especially if the height of the geometrical features is at the same size level (or higher) of the thickness of the membranes $[37,38]$. In this study, we propose the use of Layer-by-Layer (LbL) as it allows the assembly of oppositely charged elements over any substrate with a geometrical control at the nano-scale-level $[39,40]$. It was already shown that LbL could be used to coat textured surfaces with micrometer-scale features to enhance the performance of biomedical devices $[41,42]$. On the other hand, LbL was also used to process flat freestanding membranes based on chitosan (CHT) and alginate (ALG) $[12,43]$. We combined these two possibilities to produce for the first time easily detachable freestanding multilayer membranes patterned with well-defined geometrical motifs and uniquely composed by natural-based polymers. We are particularly interested in generating an array of pores with controlled geometry, size, and depth that could be adequate to accommodate cell colonization, organization and proliferation.

In this work, low surface energy polydimethylsiloxane (PDMS) templates, fabricated by UV photolithography, are used as supportive substrates to prepare patterned membranes. In the end we expect to produce polymeric membranes with well-defined geometries that can replicate the patterning of the supportive substrate with a high geometrical control, while maintaining the nano-scale control of the polymer organization along the thickness of the membrane. Such devices will be investigated as single patterned membranes but we ex- pect that they can be seen as building blocks to produce thicker tissues upon stacking different membranes, as proposed before with cell sheets [44].

\section{Materials and methods}

\subsection{Materials}

CHT of medium molecular weight $(\mathrm{Mw}=190-310 \mathrm{kDa}, 75-85 \%$ degree of deacetylation (DD), viscosity $200-800 \mathrm{cps}$ ) and ALG $(\mathrm{Mw}=538 \mathrm{kDa})$ were purchased as powder from Sigma Aldrich. CHT was submitted to a purification process, described elsewhere [45]. The polypropylene (PP) substrates used for the flat (F) control membranes were obtained from Firmo-Papéis e Papelarias S.A as A4 sheets and cut into rectangles with $\left(10 \times 4 \mathrm{~cm}^{2}\right)$. Genipin $(\mathrm{G})$ was supplied by Waco Chemicals $\mathrm{GmbH}$ in Germany and Fibronectin from Human Plasma (Fn) $\left(1 \mathrm{mg} \cdot \mathrm{ml}^{-1}\right)$ was purchased from Millipore S.A.S France. Ethanol was supplied by Fisher Chemical. Sodium Chloride $(\mathrm{NaCl})$, phosphate buffered saline (PBS), dymethil sulfoxide (DMSO), N-(3-Dimethylaminopropyl)-N'-ethylcarbodimine hydrochloride (EDC) and N-Hydroxysulfosuccinimide sodium (NHS) were obtained from Sigma Aldrich. SU-8 100 (epoxy-based negative photoresist) and SU-8 developer were purchased from Microchem. Kit Sylgard $\AA$ and 184 Silicone Elastomer (Polydimethylsiloxane PDMS) was purchased from Dow Corning.

\subsection{Build-up and real-time characterization of CHT/ALG films}

The build-up process of CHT and ALG multilayer was evaluated using a quartz crystal microbalance with dissipation monitoring (QCM-D, Q-Sense, Sweden), with a gold coated sensor excited at a fundamental frequency of $5 \mathrm{MHz}$ and eleventh overtone $(55 \mathrm{MHz})$. The crystals were cleaned by a successive washing steps with acetone, ethanol and isopropanol, in an ultrasound bath at $30{ }^{\circ} \mathrm{C}$. CHT $0.2 \%$ $(\mathrm{w} / \mathrm{v})$ and ALG $0.2 \%(\mathrm{w} / \mathrm{v})$ solutions were prepared in sodium acetate buffer $(0.1 \mathrm{M})$ in the presence of additional salt $(0.15 \mathrm{M}$ of $\mathrm{NaCl}$ solution). The $\mathrm{pH}$ of both solutions was adjusted to 5.5. The CHT solution was injected with a constant flow rate of $50 \mu \mathrm{L} \cdot \mathrm{min}^{-1}$ into the system, standing for $10 \mathrm{~min}(\mathrm{~min})$ to allow the adsorption equilibrium at the surface of the crystal. Then a sodium acetate buffer $(0.15 \mathrm{M}$ of $\mathrm{NaCl}$, $\mathrm{pH}$ 5.5) solution was pumped into the system for $10 \mathrm{~min}$. The same procedure was followed with the ALG solution for the desired number of layers. The frequency and dissipation were monitored in real time until the number of the desired layers was successfully accomplished. The Fn absorption onto the resulting system was also evaluated. A $10 \mu \mathrm{g} . \mathrm{ml}^{-1} \mathrm{Fn}$ solution was injected for approximately $2.5 \mathrm{~h}$ in the system and then washed with $\mathrm{NaCl}$ solution for $20 \mathrm{~min}$. The thickness of the film was estimated by the Q-Tools software, from Q-Sense, using the Voigt model.

\subsection{Fabrication of the freestanding multilayered films}

\subsubsection{Fabrication of the patterned SU-8 molds}

The fabrication of the SU-8 molds was done by UV photolithography and microstructures with several shapes were obtained using photomasks with the desired pattern. The SU-8 processing started with depositions of SU-8 100 over a glass slide substrate by spin coating at $2200 \mathrm{rpm}$ during $30 \mathrm{~s}$ (s) to obtain a final thickness of $220 \mu \mathrm{m}$. After this, a pre-bake was performed in a ramping hot plate for the evaporation of the solvent. This step was fulfilled in two cycles: the first pre-bake was made at $65^{\circ} \mathrm{C}$ during $30 \mathrm{~min}$ and the second cycle at $95^{\circ} \mathrm{C}$ during $70 \mathrm{~min}$. Then SU-8 was patterned by UV 
exposure (365 nm) during 8 min using a photomask with the desired pattern. Since the SU-8 was a negative photoresist, the areas exposed to the UV light remained rigid and the protected areas dissolved during the development step. After the exposure, a post-bake was performed to increase the degree of crosslinking in the SU-8 exposed areas, to make it resistant to solvents in the developing step. Similarly, to the pre-bake step, the post-bake was performed in two cycles at $65^{\circ} \mathrm{C}$ during $10 \mathrm{~min}$ followed by $95{ }^{\circ} \mathrm{C}$ during $15 \mathrm{~min}$. Finally, to remove the non-exposed area of SU-8, the structure was immersed in a SU-8 developer during $20 \mathrm{~min}$ to obtain the final mold.

\subsubsection{Fabrication of the PDMS molds}

The PDMS molds were obtained using the SU-8 mold through replica molding techniques and then used for the fabrication of the respective structures [46-50]. Usually, a SU-8 mold is used for the PDMS patterning due to its easy fabrication and high aspect ratios structures obtained using low cost UV photolithography [51]. Moreover, it is biocompatible and both mechanically and chemically stable [52]. These materials are commonly used for the fabrication of microfluidic devices for several applications [52,53], allowing patterning structures with sub-micrometric dimensions [54]. The PDMS can be cast in a SU-8 mold with high fidelity by a low cost and easy fabrication process.

A PDMS solution was done by mixing the base and curing agent in a 10:1 wt ratio. The solution was prepared in a vacuum system to remove off air bubbles generate during mixing. After that, the PDMS solution was poured over the SU-8 mold and cured at $100 \mathrm{C}$ during 20 min using an oven. Finally, the PDMS-cover SU-8 mold was cut around the structures and then peeled off the SU-8. The fabrication process of the PDMS molds is represented in Fig. 1A, highlighting the example of a template with patterned cylinders.

\subsubsection{Production of the freestanding membranes}

The CHT/ALG polyelectrolyte multilayers were constructed onto PDMS substrates or PP substrates to obtain patterned or flat membranes, respectively. The substrates were cleaned with $70 \%$ ethanol $(\mathrm{v} /$ v) and dried at room temperature, $20^{\circ} \mathrm{C}(\mathrm{RT})$. The multilayered film build-up started by immersing the substrates in CHT solution during 6 min followed by two washing steps in sodium acetate buffer $(0.15 \mathrm{M}$ of $\mathrm{NaCl}, \mathrm{pH} 5.5$ ) solution for 3 min each. Afterwards, the same procedure was followed for the ALG solution. These steps correspond to the assembly of one double layer $(\mathrm{dL})$ - see Fig. 1B. The process was repeated 100 times forming $100 \mathrm{dL}$ (200 layers), using a dipping robot especially designed for the automatic fabrication of the multilayers. The number of $\mathrm{dL}$ was defined according with the work developed by Silva et al. [12]. In the end of the cycles, the substrates were left to dry at RT until the membranes were ready to detached - see Fig. 1C. Different post-processing treatments on both patterned $(\mathrm{P})$ and flat $(\mathrm{F})$ membranes were also investigated, namely crosslinking with Genipin $(\mathrm{G})$ and/or fibronectin (Fn) adsorption, to perceive its effect when culture with osteoblastic cells - see Fig. 1D. Therefore, the following membranes were proposed: flat membranes without any treatment $(\mathrm{F})$, flat membranes with $\mathrm{Fn}(\mathrm{F}-\mathrm{Fn})$, flat membranes with $\mathrm{G}$ (F-G), flat membranes with $\mathrm{G}$ and Fn (F-GFn), multiwell membranes without any treatment $(\mathrm{P})$, multiwell membranes with Fn (P-Fn), multiwell membranes with $\mathrm{G}(\mathrm{P}-\mathrm{G})$ and multiwell membranes with $\mathrm{G}$ and Fn (P-GFn).

\subsection{Scanning Electron Microscopy (SEM)}

The morphology of (CHT/ALG) ${ }_{100}$ membranes was observed by Scanning Electron Microscopy (SEM) using a NanoSEM, Nova200 at $15 \mathrm{kV}$ accelerating voltage. All the specimens were sputter-coated with a conductive gold layer, using a sputter coater (Cressington) for $40 \mathrm{~s}$ at a current of $40 \mathrm{~mA}$. For the cross-section observation, the de-

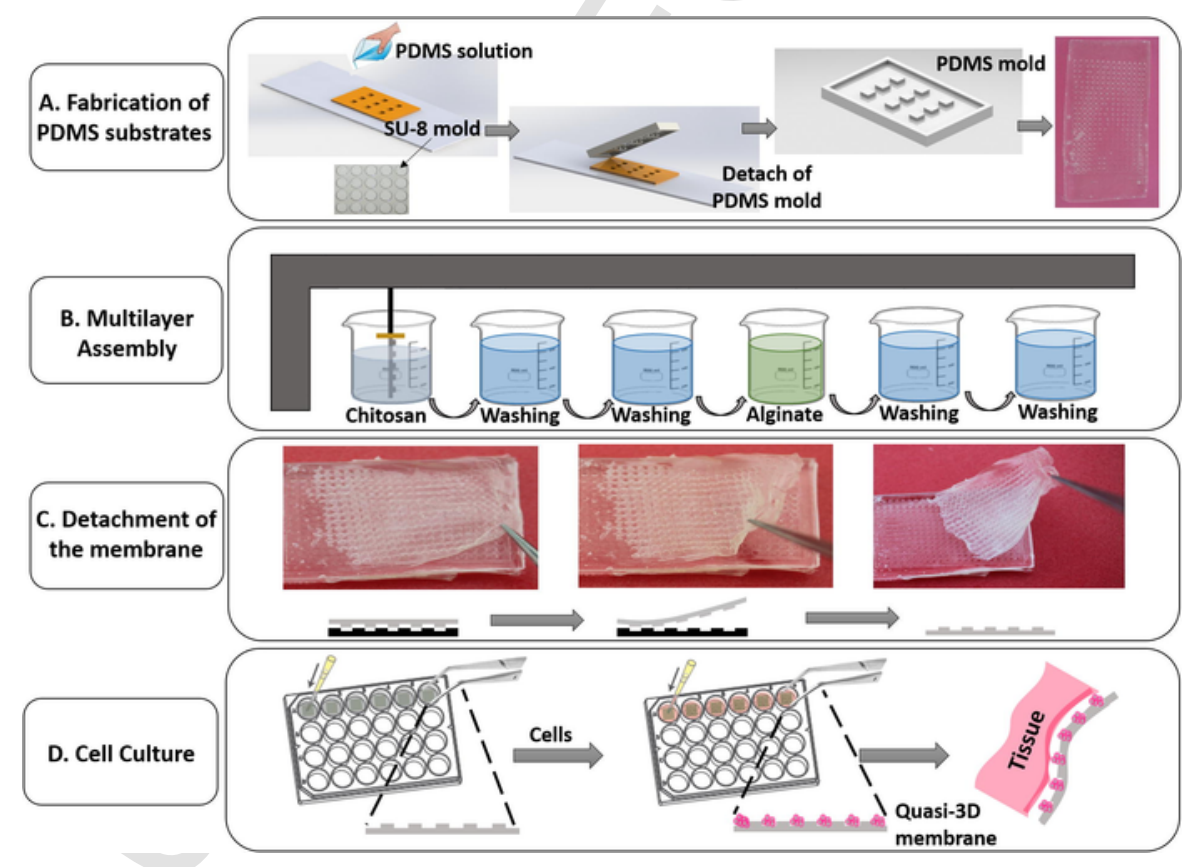

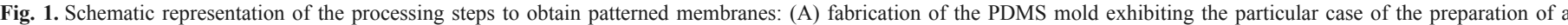

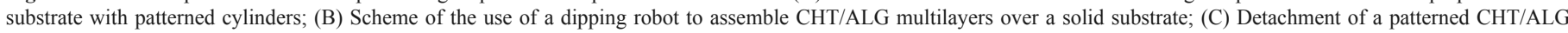

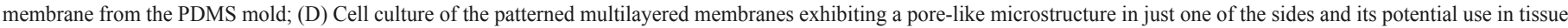
engineering. 
tached freestanding membranes were immersed in liquid nitrogen until free fracture. Three freestanding membranes were analysed for each condition ( $\mathrm{F}$ and $\mathrm{P})$.

\subsection{Chemical crosslinking with genipin $(G)$}

(CHT/ALG) $)_{100}$ membranes were crosslinked with G. A G solution $\left(1 \mathrm{mg} \cdot \mathrm{ml}^{-1}\right)$ was prepared in a mixed solution of sodium acetate buffer ( $0.15 \mathrm{M}$ of $\mathrm{NaCl}, \mathrm{pH} 5.5)$ solution and DMSO (4:1 ratio). The membranes were immersed in the prepared solution and incubated overnight at $37^{\circ} \mathrm{C}$. To stop the reaction, the membranes were dipped in absolute ethanol until the excess of $\mathrm{G}$ was removed and then dried at RT. This procedure was used to prepare membranes (F-G, F-GFn, P-G and P-GFn).

\subsection{Biological characterization}

To evaluate the biological activity of the (CHT/ALG) $)_{100}$ membranes, cell culture studies were performed with SaOs-2 human osteoblast-like cells (ECACC), which besides being fully differentiated like osteoblasts, these cells have been well characterized in the literature $[55,56]$ and reported for similar works, including studies of the interaction between curvature and cells [57]. The cells were cultured in Dulbecco's modified eagle medium (DMEM; Sigma Aldrich), supplemented with 10\% Fetal Bovine Serum (FBS; Biochrom AG) and $1 \%$ Penicillin/Streptomycin (100U/100 g.ml ${ }^{-1}$; Life Technologies). SaOs- 2 cells were used at passages 14-16. The cells were incubated at $37{ }^{\circ} \mathrm{C}$ in a humidified $5 \% \mathrm{CO}_{2}$ atmosphere and the conditioned medium was changed every two days. Upon reaching $80 \%$ confluence, cells were harvested and seeded onto the (CHT/ALG) ${ }_{100}$ membranes.

The multiwell freestanding membranes were chosen for the biological characterization part, acting as a proof-of-concept of the technology. Before seeding, the membranes were sterilized with $70 \%$ ethanol solution for $2 \mathrm{~h}$, washed twice with PBS and immersed in DMEM without FBS overnight. This pre-incubation in medium allowed to guarantee that the cells were seeded when the level of the hydration of the membranes was already stabilized. A set of samples was functionalized with Fn (P-GFn, P-Fn, F-GFn and F-Fn). The optimal immobilization conditions were based on studies previously performed to immobilize Fn on CHT substrates [58]. Briefly, the carboxyl group of the protein was pre-activated with EDC/NHS. This step was performed during $20 \mathrm{~min}$ at RT. In a second step, the activated protein reacted with primary amines of the CHT to form amide bonds, leading to the covalent attachment of the Fn. This reaction was performed at cell culture conditions $\left(37^{\circ} \mathrm{C}\right.$ and $\left.5 \% \mathrm{CO}_{2}\right)$ overnight.

Cell seeding was performed by dropping a $200 \mu \mathrm{l}$ cell suspension containing 25,000 cells per substrate $\left(1 \mathrm{~cm}^{2}\right.$ membranes $)$, above the ALG-ending side of the multilayer membranes. Besides corresponding to the concave side, previous works already reported cellular preferential adhesion on ALG-ending multilayers rather than on CHT-ending coatings [43]. After $3 \mathrm{~h}$ of incubation at cell culture conditions, fresh culture medium was added to the membranes. Tissue culture polystyrene coverslips (TCPS) were used as positive control and latex gloves were used as negative control. The medium was changed every two days to ensure the adequate source of cell nutrients. After 1, 3 and 7 days, samples were collected for cell viability assay, DNA quantification, morphological observation and nuclei quantification.

\subsubsection{MTS assay - Cellular viability}

The culture medium was removed at 1, 3 and 7 days and the samples were rinsed with sterile PBS. Serum-free culture medium was mixed with the MTS reagent in a 4:1 ratio and added to the membranes, TCPS and the negative controls (no cells or no samples). All conditions were performed in triplicate and placed in the incubator for $3 \mathrm{~h}$, at $37^{\circ} \mathrm{C}$ and $5 \% \mathrm{CO}_{2}$ atmosphere. The absorbance was measured in triplicate at $490 \mathrm{~nm}$ using a microplate reader (Synergy HT, Bio-TEK). The results were expressed through the obtained absorbance values in each condition (normalized by no cells absorbance values and specific area) as a function of the culture time. The specific surface area is the total surface area of the membrane (including the wall and the bottom of the wells) divided by the length multiplied by the width of the membranes; for flat membranes, this value is equal to 1.

\subsubsection{DNA quantification}

Cell proliferation study was performed by a fluorimetric dsDNA quantification kit (Quant-iT ${ }^{\mathrm{TM}}$, PicoGreen ${ }^{\circledR}$, Molecular Probes, Invitrogen, USA). The specimens for 1, 3 and 7 days of culture were washed twice with PBS and transferred into Eppendorf tubes containing $1 \mathrm{ml}$ of ultra-pure water. The samples were left to incubate for $1 \mathrm{~h}$ at $37{ }^{\circ} \mathrm{C}$ and $5 \% \mathrm{CO}_{2}$ humidified atmosphere and then frozen at $-80{ }^{\circ} \mathrm{C}$ until further analyses. For the DNA quantification, the samples were thawed and sonicated for $20 \mathrm{~min}$. The DNA standards were prepared at concentrations $0 \mu \mathrm{l} . \mathrm{ml}^{-1}, 0.2 \mu 1 . \mathrm{ml}^{-1}, 0.5 \mu 1 . \mathrm{ml}^{-1}, 1 \mu \mathrm{l} . \mathrm{ml}^{-1}$ and $1.5 \mu \mathrm{l} . \mathrm{ml}^{-1}$. The PicoGreen, TE buffer and the sample were added at a 96-well opaque plate (Falcon). The fluorescence was measured in a microplate reader (Synergie HT, Bio-TEK, USA) using an excitation wavelength of $480 \mathrm{~nm}$ and an emission wavelength of $528 \mathrm{~nm}$. For each sample, the DNA concentration was calculated using a standard curve that relates DNA concentration with fluorescence intensity. The results were normalized by the specific area.

\subsubsection{Morphological observation}

For the fluorescence analyses, membranes were washed with PBS, fixed in freshly prepared $10 \%$ Formalin (Thermo Fisher Scientific)/ PBS, for $30 \mathrm{~min}$ at RT, and washed extensively in PBS to remove all traces of the fixative. The samples were permeabilized with $0.2 \%$ Triton-100 (Sigma Aldrich) for $10 \mathrm{~min}$ and blocked with a $3 \%$ bovine serum albumin (BSA) (Sigma Aldrich) solution during $30 \mathrm{~min}$. The cells were then stained with $50 \mu \mathrm{g} . \mathrm{ml}^{-1}$ phalloidin solution (Sigma Aldrich) in PBS for $45 \mathrm{~min}$ and $20 \mu \mathrm{g} \cdot \mathrm{ml}^{-1}$ DAPI-conjugate solution (Sigma Aldrich) for $15 \mathrm{~min}$ at RT. The membranes were washed in PBS to remove remaining staining solutions and imaged using a transmitted and reflected light microscope with apotome 2 (Axio Imager Z1 m, Zeiss) and with Inverted Confocal Microscope with incubation (Leica, TCS SP8). The quantification of the cells nuclei was performed using NIH ImageJ software (developed at the U.S. National Institutes of Health). The established area for the calculations for both membranes was the area of one single well and its immediately surrounding in the multiwell membrane $\left(A=2.3 \mathrm{~mm}^{2}\right)$. Five measurements were taken of each condition.

\subsection{Statistical analysis}

All the experiments were performed in triplicate. The results are presented as mean \pm standard deviation (SD). Statistical significance between the different conditions was assessed using the two-way analysis of variance (ANOVA) test with Bonferroni post-test and was 
signed as $\mathrm{p}<0.05, \mathrm{p}<0.01$ and $\mathrm{p}<0.001$, using the software GraphPad Prism 7.0 for Mac.

\section{Results}

\subsection{Build-up and real-time characterization of CHT/ALG films}

The build-up of five bilayers of CHT/ALG multilayered films was accessed in situ using QCM-D. This technique detects the absorbed mass of polyelectrolytes on a gold-coated quartz sensor and measures the change in the viscoelastic properties of the surface [59]. The combination of $\Delta f$ and $\Delta D$ gives information about the adsorbed amount and the variations of the viscoelastic properties [59-61]. QCM-D results (Fig. 2A) show the build-up of $5 \mathrm{dL}$ of CHT and ALG in terms of variation on normalized frequency $\Delta f n$ (where $n$ is the frequency overtone) and dissipation, $\Delta D$. As expected, the normalized frequency decreases with each polyelectrolyte solution injection, showing the increase of mass over the gold sensor. The increase of $\Delta D_{5}$ is related to the non-rigid layer structure that was deposited over the crystal. During the washing step that follows each polyelectrolyte injection, the change of both $\Delta f_{5}$ and $\Delta D_{5}$ was relatively small comparably to the total frequency variation associated to the adsorption of the respective polymer. This indicates a strong layer association on the surface of the crystal.

To study the Fn immobilization onto the CHT/ALG membranes, a QCM-D in situ Fn immobilization study was also performed after the assembly of the $5 \mathrm{dL}$. The inset in Fig. 2A shows a slight increase in dissipation and a slight decrease in frequency associated with Fn immobilization over the membrane surface.

The thickness of the film was estimated using the Voigt Model [62]. Fig. 2B shows the thickness variation along the deposition of $5 \mathrm{dL}$ and $\mathrm{Fn}$.

\subsection{Scanning Electron Microscopy (SEM) analysis of the freestanding membranes}

CHT and ALG were successively adsorbed on the surface of the hydrophobic PDMS substrates. Upon drying, the (CHT/ALG) $)_{100}$ multilayer was easily detached from the surface to produce a robust and flexible membrane. The morphology of the freestanding membranes was evaluated by SEM (Fig. 3). The images in Fig. 3A show that different topographies were successfully reproduced onto the CHT/ALG membranes produced by LbL technique, just by changing the underlying substrate. The use of PDMS as substrate allowed the ability to create well-defined patterns with different shapes; also size and depth could be tailored. The conjugation of PDMS patterned molds and LbL created a single and direct approach to produce patterned membranes, being an easier methodology to obtain such structures than other conventional techniques $[46,48-50]$.

The thickness and internal organization of the membranes was directly observed by the cross-section SEM images - see Fig. 3B. The internal morphology of the flat membrane is homogeneous and the thickness was about $32 \pm 2.4 \mu \mathrm{m}$. Similar results were obtained for the multiwell patterned membrane. The height of the well bottom was about $23 \pm 0.89 \mu \mathrm{m}$ while for the overall membrane the thickness was about $38 \pm 2.2 \mu \mathrm{m}$; from these results, we estimated that the depth of the wells was about $15 \mu \mathrm{m}$. In addition, the cross-section SEM image of the multiwell membrane shows that cylindrical motifs patterned on the membranes present curved-shaped sides. The top-view (see Fig. 3B) of the patterned membrane showed a microscale precision in the well array design, which supports that LbL can in fact recreate different motifs with high precision.
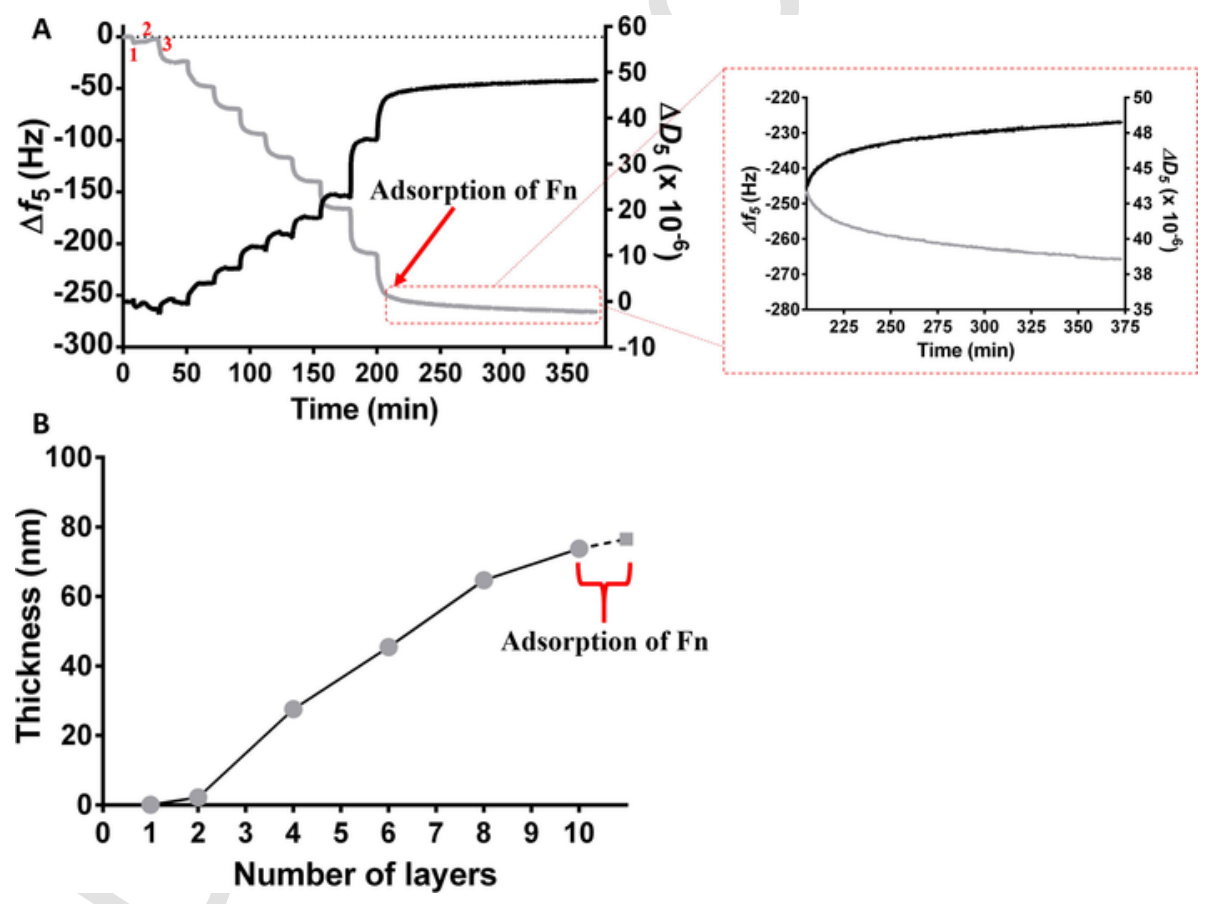

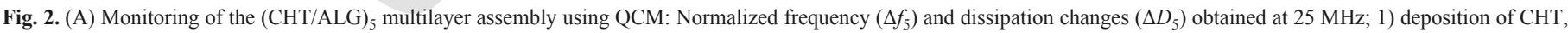

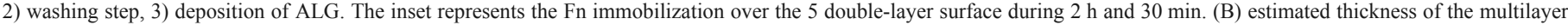
surface up to 5 double-layers (10 layers); the end of each layer is represented with a circle, and the end of the Fn immobilization is represented with a square. 

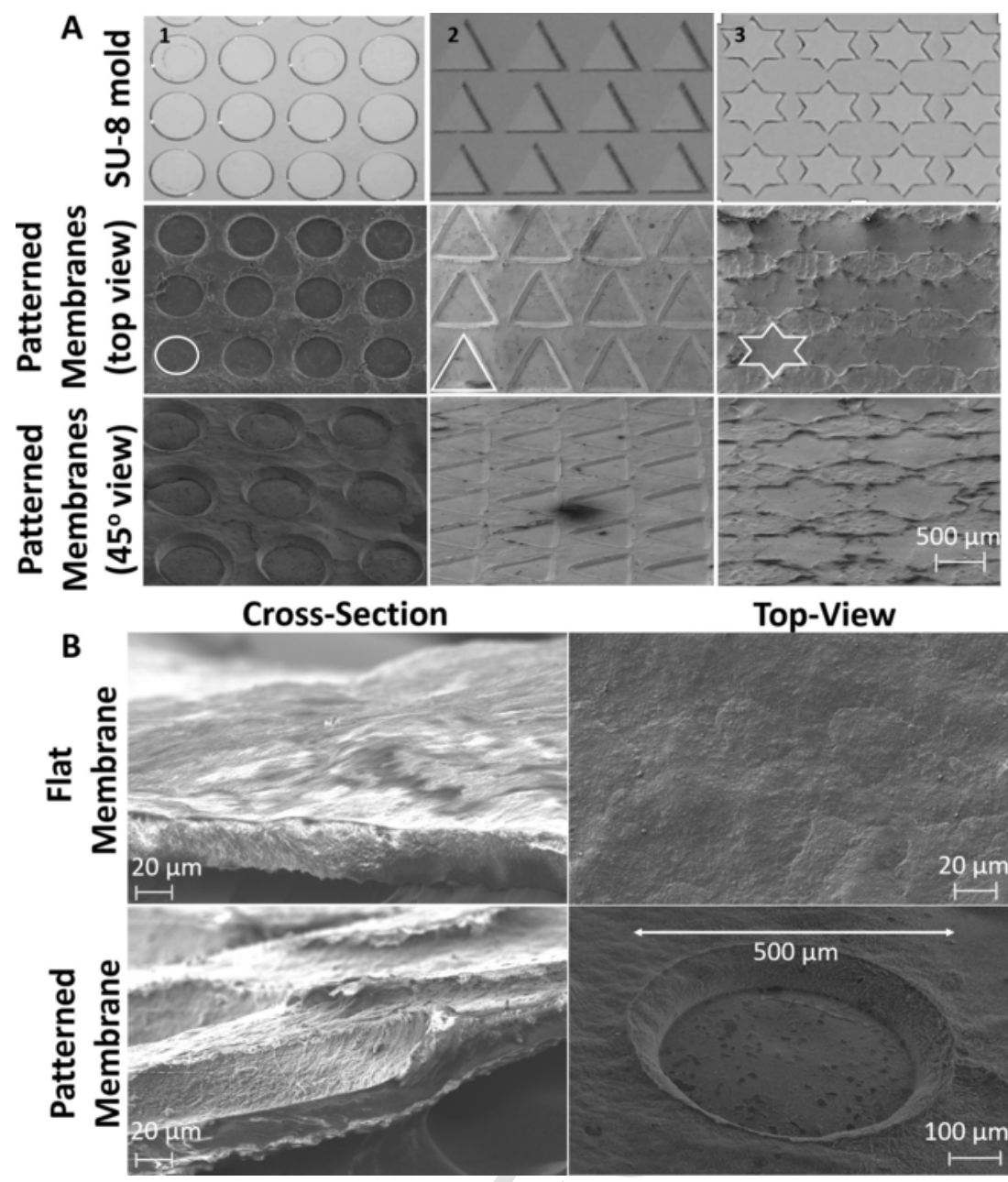

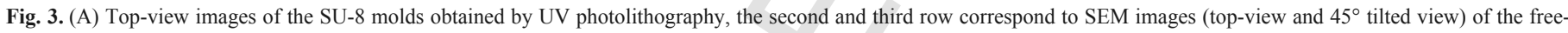

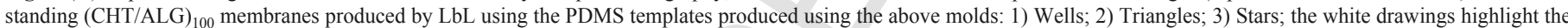
geometric feature of the obtained pattern; (B) SEM images of flat and patterned (wells) membranes: cross-sections and top-views.

\subsection{Biological assays}

Membranes patterned with cylindrical motifs were used for the biological assays. Two different methods were employed to enhance the cellular adhesion onto the (CHT/ALG) ${ }_{100}$ membranes: chemical covalent crosslinking with $\mathrm{G}$ and Fn immobilization on the surface of the membrane.

Cellular viability results were obtained using a MTS assay - see Fig. 4A. An increase in the metabolic activity of cells adhered on the membranes was observed over the time of culture. This can be an indication of no cytotoxic effects for this type of cells. For day 1, there were no significant differences between the different conditions. In day 3 and day 7, it was evident that the cells seeded on the flat membranes showed less metabolic activity compared with the cells seeded on the patterned ones.

Cell proliferation was evaluated by DNA quantification - see Fig. 4B. The results obtained for the flat and patterned membranes showed that the number of cells increased with the culture time. All these data were normalized by the specific area of the flat membranes, to minimize the surface area effect. Cell culture in the patterned membranes displayed a clear enhancement in cell proliferation after 7 days of culture when compared with the flat ones. In day 3 of culture it was possible to observe that the P-GFn membrane presented a significant higher number of cells than the other conditions. The DNA content of cells seeded above P-G and F-GFn presents approximate values. For day 7 it was possible to observe that the flat membranes $(F)$ had the lowest values of cellular density. There are also evidences that cells adhered on P-GFn continued to proliferate, considering the higher values of DNA content. Nuclei quantification was also estimated - see Fig. 4C. After 7 days in culture it is clear that among all the formulations, the P-GFn membranes show the higher cell content.

To better understand the influence of the patterns, cell morphology was further evaluated by fluorescence and confocal microscopy. Actin filaments of the cytoskeleton were labelled with phalloidin and the DNA stained with DAPI. For flat membranes, the cells seemed to be homogeneously distributed over the surface - see Fig. 5A. Though, when the flat films are crosslinked with $G$ and modified with Fn, cell density could be increased. For the patterned membranes, a distinguishing behavior could be observed - see Fig. 5B. Since day 1, it was clear that the cells migrated to the wells of the membranes and started to agglomerate, initially in the borders of the wells and then proliferated towards the centre. For the same area, the wells showed higher number of cells comparatively with the flat regions between the wells. In $G$ and Fn conditions, the cells were well 


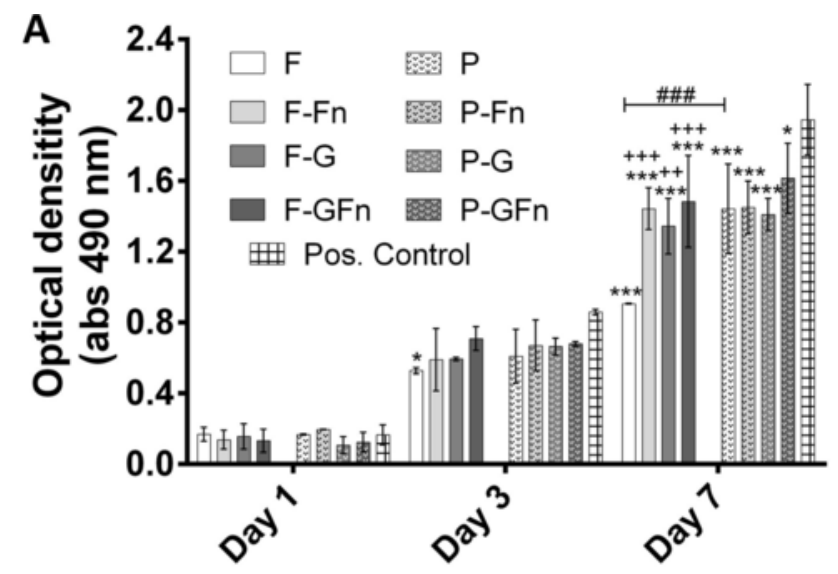

spread and anchored to the membranes, presenting a higher percentage of covered area. In conditions without $\mathrm{G}$ and Fn, the cells appeared to be in a rounder shape. Fig. 5C shows a general view of a patterned P-GFn membrane after 7 days of culture, where it is evident the cell migration towards the wells on the membrane.

Confocal imaging was used to evaluate with more detail cell morphology and distribution in the patterned membranes as well as the cell-material/wells interaction. Clearly, the cells presented a well spread morphology and started to aggregate in the edges of the wells - see Fig. 6. Such organization is better perceived for 3 days of culture. With increasing culturing time, the cells proliferated towards the centre and after 7 days, they presented highly confluence density. The P-GFn condition presented more cells adhered and more confluent spots comparatively with the P-G, which sustains the good combined effect of $\mathrm{G}$ and $\mathrm{Fn}$ in the cellular adhesion.

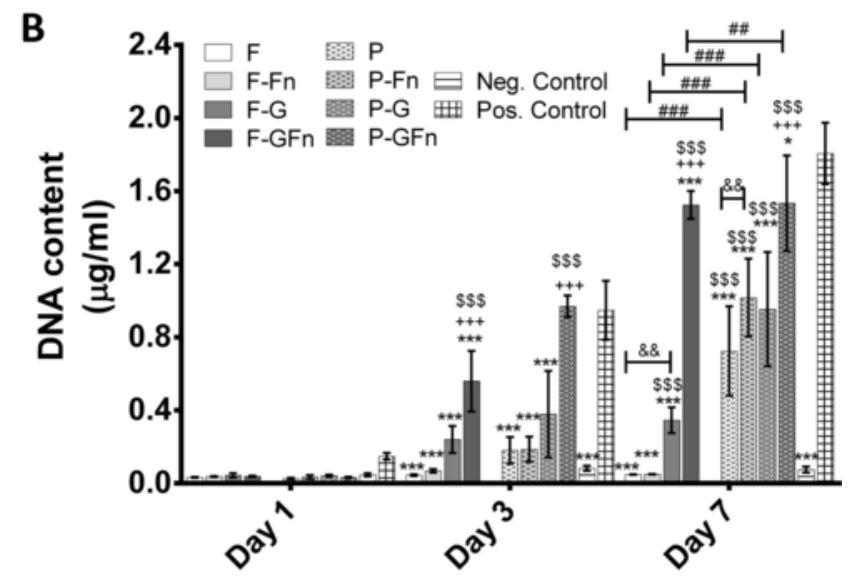

\section{Discussion}

This study demonstrates an innovative approach to produce quasi-3D freestanding membranes that exhibit well arrays in one side of the membrane. Such array can be tuned with various sizes and geometries features that will affect cell function and can be critical to their successful application in tissue regeneration. Unlike conventional patterned materials, the (CHT/ALG) ${ }_{100}$ micropatterned membranes herein developed are flexible and robust, easily to produce and to incorporate different topographic features.

Using LbL assembly of polyelectrolyte systems like CHT and ALG we could produce multilayer films. The CHT/ALG film construction was confirmed experimentally by QCM-D monitoring. The polyelectrolyte mass deposition over the crystal after each injection was confirmed by the decrease of the normalized frequency. The non-rigid behavior of the film is mainly related with the nature of the polymers and could be an important characteristic for the implantation of the membrane in the target tissue. This could be justified by the fact that in the multilayers, in hydrated conditions, the biopolymers are above their glass transition temperature, and could even exhibit shape memory ability triggered by water [63]. Furthermore, modelling QCM-D results allowed to conclude about the thickness of the films with the increase of dL. These results revealed an increase of thickness over time with the successive addition of CHT and ALG solutions which indicates the successful assembly of the multilayer film. Electrostatic interactions between CHT and ALG are mainly responsible for the construction of the multilayer film, though other interactions like hydrophobic and hydrogen bonds may also play a role $[64,65]$. By the end of the $5 \mathrm{dL}$, the Fn immobilization was performed, and a slightly decrease in frequency can be observed as well as a slightly increase of the estimated thickness, which indicate that the Fn was successfully immobilized in the membrane.

Increasing the number of $\mathrm{dL}$ we were able to produce multilayer

Fig. 4. MTS assay (A), DNA quantification (B) and Nuclei quantification (Area $=2.3$ $\left.\mathrm{mm}^{2}\right)(\mathrm{C})$ on the flat and patterned membranes with SaOs-2 cells. In the MTS assay, data was considered to be statistically significant for $\mathrm{p}<0.001(* * *)$ and for $\mathrm{p}<0.05$ $(*)$ when compare the different conditions with the positive control. For day 7 , statistical significant differences were also found between $F$ membranes and the modified

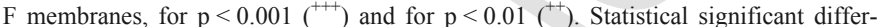
ences were found for $\mathrm{p}<0.001\left({ }^{\# \#}\right)$ when compare flat and patterned membranes. In DNA quantification, data was considered statistically different for $\mathrm{p}<0.001(* * *)$ and $\mathrm{p}<0.05\left(^{*}\right)$ when compare the positive control with the remaining conditions. F-GFn was found as statistically different when compared with the remaining flat conditions for $\mathrm{p}<0.001\left({ }^{+++}\right)$. P-GFn was found as statistically different when compared with the remaining patterned conditions for $\mathrm{p}<0.001\left(^{+++}\right)$. Significant differences were found for $p<0.001(\$ \$ \$)$ between negative control and the remaining conditions. Significant differences were also found for $\mathrm{p}<0.001\left({ }^{\# \#}\right)$ and $\mathrm{p}<0.01\left({ }^{\# \#}\right)$ between the different flat and patterned conditions. Finally, data was considered statistically significant for $\mathrm{p}<0.01\left({ }^{\& \&}\right)$. In nuclei quantification, statistical significant differences were found for $\mathrm{p}<0.001\left(^{* * *}\right)$ and $\mathrm{p}<0.05(\hat{)})$ between positive control and the remaining conditions. Data was also considered statistically significant for $\mathrm{p}<0.001(\# \#)$. ble to be detached, as already reported elsewhere [12]. SU-8 molds made by photolithography can produce features down to $5 \mu \mathrm{m}$, as already been reported in literature [51] and playing with the concentration of commercial PDMS, it is possible to cast this polymer in the micro to sub-millimeter patterned SU-8 with high fidelity. A single SU- 8 mold can be reuse at least 50 times to obtain the PDMS templates, being a technique with high replication fidelity and reproducibility. The use of such kind of texturized underlying substrate allowed to create membranes with patternings containing different shapes; also, size and depth could be tuned. The conjugation between PDMS substrates and LbL created a single and direct approach to produce patterned membranes, being an easier methodology to obtain 

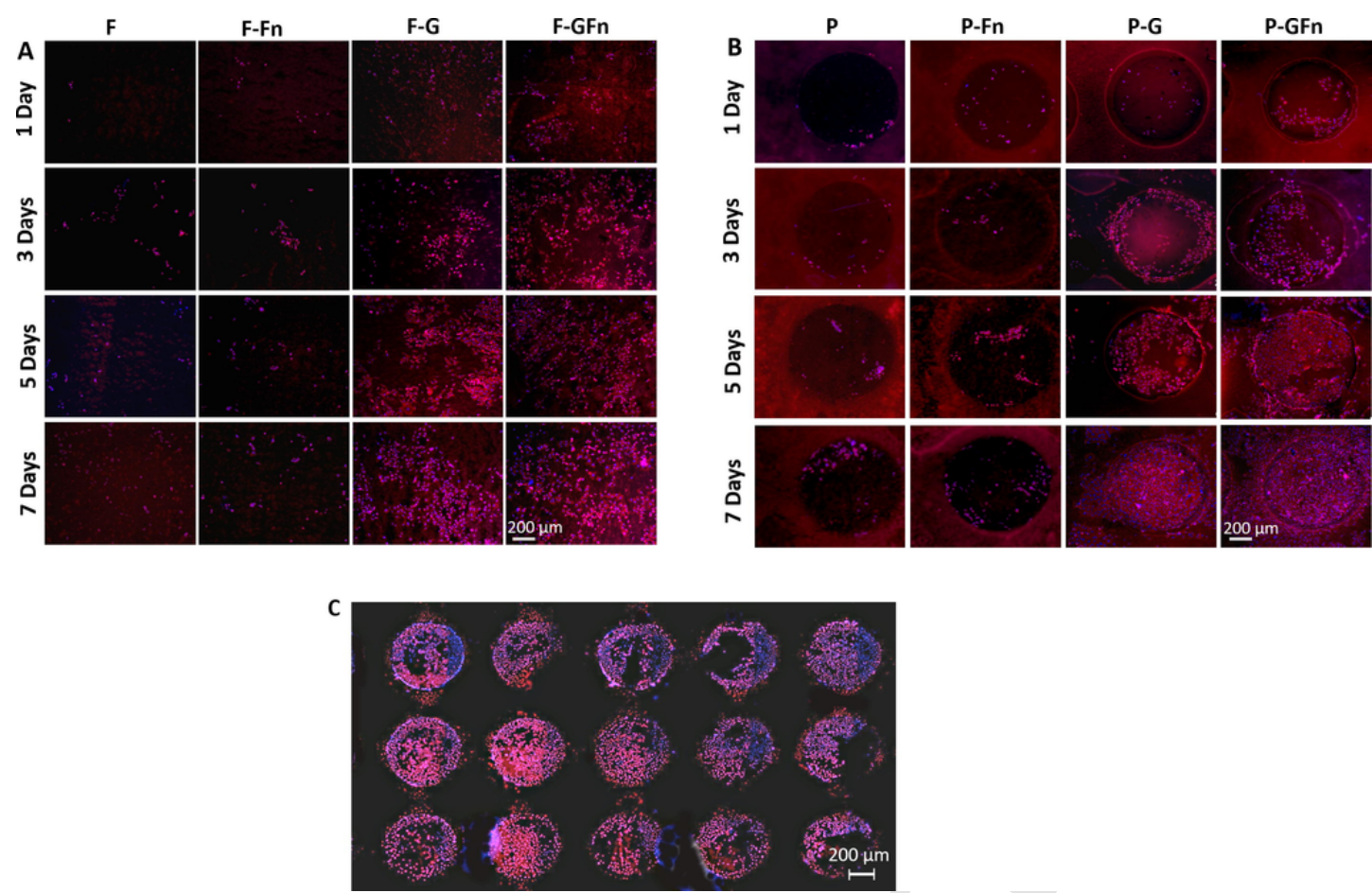

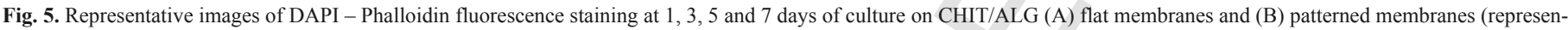

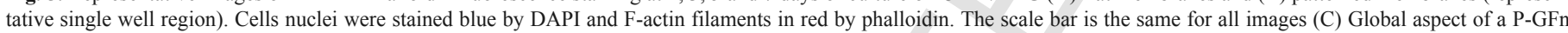
membrane upon 7 days of culture. (For interpretation of the references to colour in this figure legend, the reader is referred to the web version of this article.)

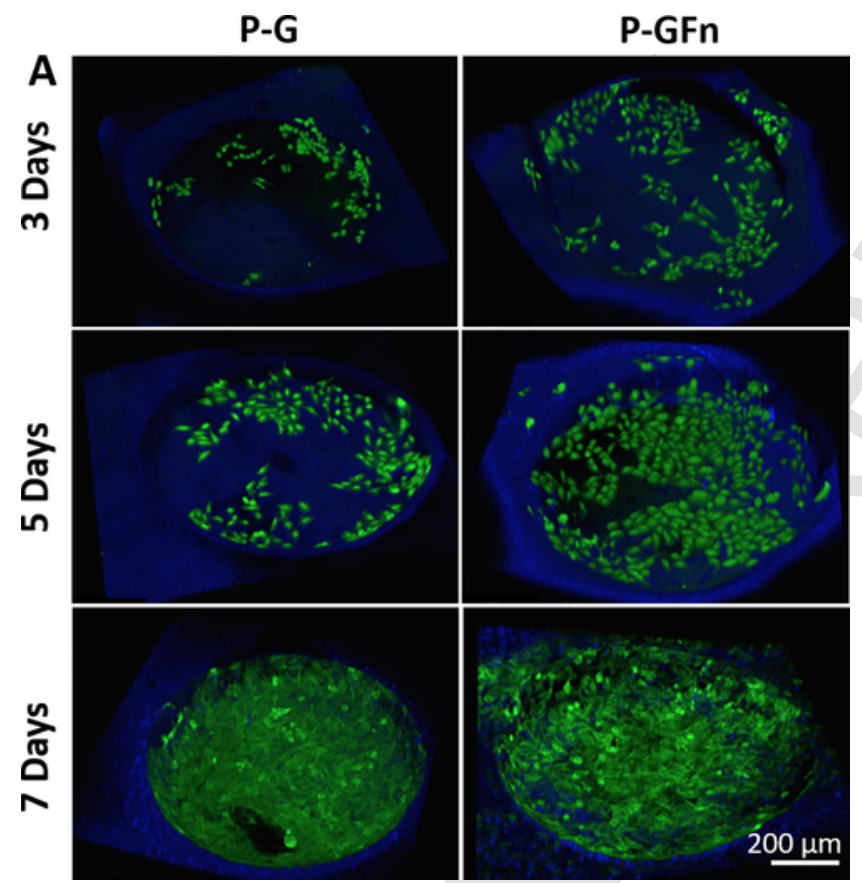

Fig. 6. Representative images obtained by confocal microscopy of the well region of the P-G and P-GFn membranes. The cells nuclei were stained blue by DAPI and F-actin filaments in green by phalloidin. (For interpretation of the references to colour in this figure legend, the reader is referred to the web version of this article.)

such structures than other reported methodologies [48,49]. Different geometrical features were successfully reproduced on the freestanding multilayer membranes, showing the reproducibility of this technology with different geometrical features, even with sharp or smooth edges. Regarding the thickness of the membranes, similar results were obtained for the flat and the patterned membranes. Moreover, comparing the morphologies of the flat and patterned membranes (in the bottom of the well), one can be observed considerable similarities, with both presenting sub-micrometer rough structures on their surface. Regarding the crosslinking step, previous studies [12] had already shown that film's properties like oxygen and glucose permeability, Young modulus and cell adhesion could be tailored by genipin concentration. Herein, we worked with a concentration of $1 \mathrm{mg} / \mathrm{ml}$ of genipin, as it seemed to result in the best commitment for soft tissue engineering applications [12]. A homogeneous distribution of the crosslinking degree was found either for flat or for patterned membranes, without any sign of crosslinker accumulation in the wells. This assumption was based on the blue color intensity observed when the membranes were crosslinked with genipin [66]. Properties like storage modulus, diffusion, maximum hydrostatic pressure and Young modulus were previously investigated for $1 \mathrm{mg} /$ $\mathrm{ml}$ of genipin crosslinked freestanding multilayered membranes made of chitosan and alginate [12]. Also cellular behavior can be modulated by crosslinking with genipin $[12,67]$; at ideal concentrations, the crosslink with genipin allowed the stiffness of the membranes to increase and, thus, the water uptake to decrease and the protein adsorption to increase, enhancing the cell adhesive properties of the multilayers membranes.

It was already reported that Fn immobilization on CHT surfaces through covalent bonding, has positive effects in cell attachment and proliferation [58]. We hypothesize that such treatment could also lead to a better cellular behavior in the multilayer membranes. Fn immobilization on the membranes was achieved using EDC/NHS chemistry. In this investigation, cell studies showed that cell behavior in multilayer films is dependent on the crosslinking with $G$ and chemical conjugation of Fn. As expected, cells adhered on multilayers crosslinked with $\mathrm{G}$ and/or functionalized with Fn, showed higher val- 
ues of cellular attachment and proliferation, which supports the increase of metabolic activity.

Regarding the effect of the patterning in cell behavior for the first day of culture, the cells already adhered to the substrate and started to communicate with each other and proliferate, in both flat and patterned multilayer membranes. However, for the following days in culture, the quasi-3D patterned membranes showed higher cell proliferation comparing with flat substrates, even without CL and G. We hypothesize that this difference in cell proliferation can be a consequence of cells perceiving the patterned membranes as quasi-3D geometrical environment, with highly selective cell grouping. Reinforcing the results from MTS and DNA quantification, also fluorescence microscopic images show that for the same area, the patterned region (well) shows higher density of attached cells comparatively with the flat membrane. Confocal microscopic images show the cell-material/wells interactions in more detail. Initial cell interaction with the surface of the membranes could occur firstly by non-specific bindings (such as electrostatic interactions) and then by specific bindings, mainly mediated by integrin, which will recruit the consequent receptor-ligand and enhance the number of cells attached to the substrate [68]. Along with the days of culture, the cells continued to spread on the wells, increasing the contact area between cells and material; this process results from the continuing adhesion and restructuring of the actin skeleton of the cells and focal adhesion formation [68]. After 7 days of culture, the cells seemed to achieve the maximum spread area, enhancing the total adhesion strength.

In fact, the interaction between cells and surfaces can be also understood through different mechanisms, as surface area, geometry and shape that can trigger different responses. Surface area and pore size are important topological characteristics of materials when in extracellular environmental. Increasing the projected surface area of scaffolds has been a strategy to increase the possible binding sites for the initial cellular attachment [30,33]. A linear relation was reported [33] between MC3T3 cells attachment and projected surface area.

In the work herein presented, the existence of the micro-patterned wells allowed to increase the specific surface area of (CHT/ALG) $)_{100}$ membranes. Our results follow the same trend as the reported works, as SaOs-2 adhered more on the patterned (CHT/ALG) $)_{100}$ membranes, with higher specific surface area. The geometry of the surface influences the spatial distribution of cellular focal adhesions and in this way also the morphology, proliferation and even differentiation of cells $[18,69]$. In our study, the micro-fabricated wells provided a better environment for cellular adhesion, higher rates of proliferation as well as better cellular distribution over the surface, concentrated firstly in the sides of the wells and then in the bottom of the wells. This phenomenon is related not only with the shape but also with the curvature of the geometric features. Some groups [70,71] reported the ability to control the growth of biological tissues just by controlling the shape and the curvature of the pores. Graziano et al. [71] produced synthetic scaffolds containing concave micro-cavities capable to induce higher neo-formation of bone tissue than the flat scaffold; the authors argued that concave shapes may facilitate the release of more biologically relevant and coordinated amounts of growth factors. Deeper knowledge of the impact of surface curvature on cell function is still missing. Few studies have been exploring mechanistic models capable of modelling cytoskeletal changes in response to external geometrical cues. Bidan et al. $[35,36]$ investigated the effect of material's geometry and curvature, patterned at a sub-millimeter scale, on tissue growth. A chord model predicted the interfacial motion of tissue growth on patterned materials; the results [35] suggested that in the presence of semi-circular channels MC3T3-E1 were growing layer-by-layer from the periphery (higher curvature areas) until the curvature of the surface becomes zero. Our results were in accordance with these investigations. Cell migration was clearly affected by the presence of the wells on the membrane; the presence of the geometrical cues led cells to migrate and start to adhere in the borders of the wells and proliferate to the centre direction. A recent study [72] shown that the diameter of 3D spherical pores could has influence on cellular morphological changes and osteogenic differentiation, even when curvatures are much larger than cell size. Herein, we developed concave spherical structures with a diameter of $500 \mu \mathrm{m}$ (principle curvature $(\kappa)=1 / 250 \mu \mathrm{m}^{-1}$ ), much larger than the size of SaOs-2 cell in a spread shape. Confocal microscopy of stained osteoblasts provided more details about the cellular morphological changes on the curvature-patterned membranes. In first days of culture, intense actin filaments were observed on the concave areas of the membrane, mostly with an inward shape direction. We hypothesize that besides to the $x-y$ stretching, which also exists on the flat 2D membranes, the existence of the concave geometrical structures on the quasi-3D membranes allowed cells to stretch upward in the $\mathrm{z}$ direction. Rausch et al. [73] suggested that cytoskeleton stress accumulation increases the probability of collective cell motility and migration. Herein also the stress is directed radially towards the bulk.

Overall, these featured membranes maintained a balance between specific surface area, geometry and curvature, essential for cell attachment, proliferation and migration. Even with such sub-millimeter structures we demonstrated that the patterning modulated the cellular behavior, in terms of proliferation and migration. We hypothesize that the assembly of groups of cells in contact with the tissue could stimulate the regenerative process by producing new tissue at the contact site or release bioactive proteins. The special design of the device prevents the loss of cells from the other side of the membrane.

\section{Conclusion}

In this study, using a simple and single methodology, we were able to produce quasi-3D freestanding multilayer membranes exhibiting patterned features with a microscale control. The geometrical features were easily created using PDMS molds as substrates to support the $\mathrm{LbL}$ assembly. The geometrical control of the patterned membranes, together with the nano-scale regulation of the polymeric organization along the thickness allowed to engineer multilayered membranes exhibiting a pore-like microstructure in just one of the sides. The in vitro biological results showed the patterned (CHT/ALG) $)_{100}$ membranes had effectively influence on the cellular behavior, where cells migrated specifically to the wells. Besides, the presence of the wells allowed higher rates of proliferation as well as better cellular distribution over the substrates. Furthermore, the patterned membranes could be subjected to post-treatment procedures, such crosslinking and immobilization of cell-adhesive proteins, enhancing even more cell response. Harnessing the potential of this system and technology, particular interest should be given in the soft tissues regeneration field: the presence of the wells would permit the development of 2D-like devices gathering organized cells with spatial control and micro-scale definition that could face the region of the tissue to regenerate. The design of the membrane prevents any loss of cells through the other side, thus enhancing the efficiency of cell delivery to the site. Further studies could relate curvature parameters with the morphological changes and migration speed of the cells and exploit the extent of those kind of platforms on the mineralization and formation of in vitro bone tissue. 


\section{Acknowledgments}

FC and JFM would like to thank Region Lorraine, FEDER and Mines Nancy for their financial support. MS and CAC acknowledge the Portuguese Foundation for Science and Technology (FCT) for financial support through SFRH/BD/97606/2013 and SFRH/BPD/ 100594/2014 grant. VCP, PJS and GM acknowledge FCT for the financial support through the reference project UID/EEA/04436/2013 and FEDER funds through the COMPETE 2020 - with the reference project POCI-01-0145-FEDER-006941.

\section{References}

[1] D.W. Hutmacher, Scaffold design and fabrication technologies for engineering tissues-state of the art and future perspectives, J. Biomater. Sci. Polym. Ed. 12 (2001) 107-124.

[2] M.E. Kolewe, H. Park, C. Gray, X. Ye, R. Langer, L.E. Freed, 3D structural patterns in scalable, elastomeric scaffolds guide engineered tissue architecture, Adv. Mater. 25 (2013) 4459-4465.

[3] N.D. Gkranias, F. Graziani, A. Sculean, N. Donos, Wound healing following regenerative procedures in furcation degree III defects: histomorphometric outcomes, Clin. Oral Investig. 16 (2012) 239-249.

[4] S.S. Silva, E.G. Popa, M.E. Gomes, M. Cerqueira, A.P. Marques, S.G. Caridade, P. Teixeira, C. Sousa, J.F. Mano, R.L. Reis, An investigation of the potential application of chitosan/aloe-based membranes for regenerative medicine, Acta Biomater. 9 (2013) 6790-6797.

[5] D. Kai, M.P. Prabhakaran, G. Jin, S. Ramakrishna, Polypyrrole-contained electrospun conductive nanofibrous membranes for cardiac tissue engineering, J. Biomed. Mater. Res. A 99 A (2011) 376-385.

[6] M. Griffith, W.B. Jackson, N. Lagali, K. Merrett, F. Li, P. Fagerholm, Artificial corneas: a regenerative medicine approach, Eye (Lond) 23 (2009) 1985-1989.

[7] X. Shi, T. Fujie, A. Saito, S. Takeoka, Y. Hou, Y. Shu, M. Chen, H. Wu, A. Khademhosseini, Periosteum-mimetic structures made from freestanding microgrooved nanosheets, Adv. Mater. 26 (2014) 3290-3296.

[8] S.G. Caridade, C. Monge, J. Almodóvar, R. Guillot, J. Lavaud, V. Josserand, J.L. Coll, J.F. Mano, C. Picart, Myoconductive and osteoinductive free-standing polysaccharide membranes, Acta Biomater. 15 (2015) 139-149.

[9] A. Bilir, B. Aybar, S.H. Tanrikulu, H. Issever, S. Tuna, Biocompatibility of different barrier membranes in cultures of human CRL 11372 osteoblast-like cells: an immunohistochemical study, Clin. Oral Implants Res. 18 (2007) 46-52.

[10] D.S. Thoma, G.A. Halg, M.M. Dard, R. Seibl, C.H.F. Hammerle, R.E. Jung, Evaluation of a new biodegradable membrane to prevent gingival ingrowth into mandibular bone defects in minipigs, Clin. Oral Implants Res. 20 (2009) 7-16.

[11] M.A. Alvarez-Perez, V. Guarino, V. Cirillo, L. Ambrosio, Influence of gelatin cues in PCL electrospun membranes on nerve outgrowth, Biomacromolecules 11 (2010) 2238-2246.

[12] J.M. Silva, A.R.C. Duarte, S.G. Caridade, C. Picart, R.L. Reis, J.F. Mano, Tailored freestanding multilayered membranes based on chitosan and alginate, Biomacromolecules 15 (2014) 3817-3826.

[13] I.B. Bischofs, U.S. Schwarz, Cell organization in soft media due to active mechanosensing, Proc. Natl. Acad. Sci. U.S.A. 100 (2003) 9274-9279.

[14] K. Anselme, M. Bigerelle, On the relation between surface roughness of metallic substrates and adhesion of human primary bone cells, Scanning 36 (2014) $11-20$.

[15] P. Clark, P. Connolly, A.S. Curtis, J.A. Dow, C.D. Wilkinson, Topographical control of cell behaviour: II. Multiple grooved substrata, Development 108 (1990) 635-644

[16] C.S. Chen, M. Mrksich, S. Huang, G.M. Whitesides, D.E. Ingber, Geometric control of cell life and death, Science 276 (1997) 1425-1428.

[17] M. Théry, A. Pépin, E. Dressaire, Y. Chen, M. Bornens, Cell distribution of stress fibres in response to the geometry of the adhesive environment, Cell Motil. Cytoskel. 63 (2006) 341-355.

[18] K.A. Kilian, B. Bugarija, B.T. Lahn, M. Mrksich, Geometric cues for directing the differentiation of mesenchymal stem cells, Proc. Natl. Acad. Sci. U.S.A. 107 (2010) 4872-4877.

[19] K.A. Diehl, J.D. Foley, P.F. Nealey, C.J. Murphy, Nanoscale topography modulates corneal epithelial cell migration, J. Biomed. Mater. Res. A 75 (2005) 603-611.

[20] J.Y. Lim, H.J. Donahue, Cell sensing and response to micro- and nanostructured surfaces produced by chemical and topographic patterning, Tissue Eng. 13 (2007) 1879-1891.

[21] D.H. Kim, K. Han, K. Gupta, K.W. Kwon, K.Y. Suh, A. Levchenko, Mechanosensitivity of fibroblast cell shape and movement to anisotropic substratum topography gradients, Biomaterials 30 (2009) 5433-5444.
[22] M. Nikkhah, F. Edalat, S. Manoucheri, A. Khademhosseini, Engineering microscale topographies to control the cell-substrate interface, Biomaterials 33 (2012) 5230-5246.

[23] S.K. Mitra, D. Hanson, D.D. Schlaepfer, Focal adhesion kinase: in command and control of cell motility, Nat. Rev. Mol. Cell Biol. 6 (2005) 56-68.

[24] A.S. Curtis, C.D. Wilkinson, Reactions of cells to topography, J. Biomater. Sci Polym. Ed. 9 (1998) 1313-1329.

[25] R.G. Flemming, C.J. Murphy, G.A. Abrams, S.L. Goodman, P.F. Nealey, Effects of synthetic micro- and nano-structured surfaces on cell behavior, Biomaterials 20 (1999) 573-588.

[26] E. Sardella, P. Favia, R. Gristina, M. Nardulli, R. d'Agostino, Plasma-aided micro- and nanopatterning processes for biomedical applications, Plasma Process. Polym. 3 (2006) 456-469.

[27] M.J. Dalby, M.O. Riehle, S.J. Yarwood, C.D.W. Wilkinson, A.S.G. Curtis, Nucleus alignment and cell signaling in fibroblasts: response to a micro-grooved topography, Exp. Cell. Res. 284 (2003) 274-282.

[28] S. Sarkar, G.Y. Lee, J.Y. Wong, T.A. Desai, Development and characterization of a porous micro-patterned scaffold for vascular tissue engineering applications, Biomaterials 27 (2006) 4775-4782.

[29] M. Ghibaudo, L. Trichet, J. Le Digabel, A. Richert, P. Hersen, B. Ladoux, Substrate topography induces a crossover from $2 \mathrm{D}$ to $3 \mathrm{D}$ behavior in fibroblast $\mathrm{mi}$ gration, Biophys. J. 97 (2009) 357-368.

[30] C.M. Murphy, M.G. Haugh, F.J. O'Brien, The effect of mean pore size on cell attachment, proliferation and migration in collagen-glycosaminoglycan scaffolds for bone tissue engineering, Biomaterials 31 (2010) 461-466.

[31] J. Zeltinger, J.K. Sherwood, D.A. Graham, R. Mueller, L.G. Griffith, Effect of pore size and void fraction on cellular adhesion, proliferation, and matrix deposition, Tissue Eng. 7 (2001) 557-572.

[32] J.-P. St-Pierre, M. Gauthier, L.-P. Lefebvre, M. Tabrizian, Three-dimensional growth of differentiating MC3T3-E1 pre-osteoblasts on porous titanium scaffolds, Biomaterials 26 (2005) 7319-7328.

[33] F.J. O'Brien, B.A. Harley, I.V. Yannas, L.J. Gibson, The effect of pore size on cell adhesion in collagen-GAG scaffolds, Biomaterials 26 (2005) 433-441.

[34] P. Kollmannsberger, C.M. Bidan, J.W.C. Dunlop, P. Fratzl, The physics of tissue patterning and extracellular matrix organisation: how cells join forces, Soft Matter 7 (2011) 9549-9560.

[35] C.M. Bidan, K.P. Kommareddy, M. Rumpler, P. Kollmannsberger, Y.J.M. Brechet, P. Fratzl, J.W.C. Dunlop, How linear tension converts to curvature: geometric control of bone tissue growth, PLoS One 7 (2012) 11.

[36] C.M. Bidan, K.P. Kommareddy, M. Rumpler, P. Kollmannsberger, P. Fratzl, J.W.C. Dunlop, Geometry as a factor for tissue growth: towards shape optimization of tissue engineering scaffolds, Adv. Healthcare Mater. 2 (2013) 186-194.

[37] L. Lu, A.G. Mikos, The importance of new processing techniques in tissue engineering, MRS Bull. 21 (1996) 28-32.

[38] S. Yang, K.F. Leong, Z. Du, C.K. Chua, The design of scaffolds for use in tissue engineering. Part I. Traditional factors, Tissue Eng. 7 (2001) 679-689.

[39] Z. Tang, Y. Wang, P. Podsiadlo, N.A. Kotov, Biomedical applications of layer-by-layer assembly: from biomimetics to tissue engineering, Adv Mater. 18 (2006) 3203-3224

[40] M.M. De Villiers, D.P. Otto, S.J. Strydom, Y.M. Lvov, Introduction to nanocoatings produced by layer-by-layer (LbL) self-assembly, Adv. Drug Deliv. Rev. 63 (2011) 701-715.

[41] S. Kidambi, N. Udpa, S.A. Schroeder, R. Findlan, I. Lee, C. Chan, Cell adhesion on polyelectrolyte multilayer coated polydimethylsiloxane surfaces with varying topographies, Tissue Eng. 13 (2007) 2105-2117.

[42] P.C. Demuth, X. Su, R.E. Samuel, P.T. Hammond, D.J. Irvine, Nano-layered microneedles for transcutaneous delivery of polymer nanoparticles and plasmid DNA, Adv. Mater. 22 (2010) 4851-4856.

[43] S.G. Caridade, C. Monge, F. Gilde, T. Boudou, J.F. Mano, C. Picart, Free-standing polyelectrolyte membranes made of chitosan and alginate, Biomacromolecules 14 (2013) 1653-1660.

[44] Y. Haraguchi, T. Shimizu, T. Sasagawa, H. Sekine, K. Sakaguchi, T. Kikuchi, W. Sekine, S. Sekiya, M. Yamato, M. Umezu, T. Okano, Fabrication of functional three-dimensional tissues by stacking cell sheets in vitro, Nat. Protoc. 7 (2012) 850-858.

[45] J.F. Mano, Viscoelastic properties of chitosan with different hydration degrees as studied by dynamic mechanical analysis, Macromol. Biosci. 8 (2008) 69-76.

[46] T.H. Park, M.L. Shuler, Integration of cell culture and microfabrication technology, Biotechnol. Prog. 19 (2003) 243-253.

[47] B. Ziaie, A. Baldi, M. Lei, Y. Gu, R.A. Siegel, Hard and soft micromachining for BioMEMS: review of techniques and examples of applications in microfluidics and drug delivery, Adv. Drug Deliv. Rev. 56 (2004) 145-172.

[48] P.M. Mendes, C.L. Yeung, J.A. Preece, Bio-nanopatterning of surfaces, Nanoscale Res. Lett. (2007) 373-384.

[49] C.M. Kolodziej, H.D. Maynard, Electron-beam lithography for patterning biomolecules at the micron and nanometer scale, Chem. Mater. 24 (2012) 774-780.

[50] A.M. Bowen, M.J. Motala, J.M. Lucas, S. Gupta, A.J. Baca, A. Mihi, A.P. Alivisatos, P.V. Braun, R.G. Nuzzo, Triangular elastomeric stamps for optical applications: near-field phase shift photolithography, 3D proximity field pat- 
terning, embossed antireflective coatings, and SERS Sensing, Adv. Funct. Mater. 22 (2012) 2927-2938.

[51] V. Pinto, P. Sousa, V. Cardoso, G. Minas, Optimized SU-8 processing for low-cost microstructures fabrication without cleanroom facilities, Micromachines 5 (2014) 738-755.

[52] P.K. Dey, B. Pramanick, A. Ravi Shankar, P. Ganguly, S. Das, Microstructuring of SU-8 resist for mems and bio-applications, Int. J. Smart Sensing Intell. Syst. 3 (2010) 118-129.

[53] V.F. Cardoso, S.O. Catarino, J. Serrado Nunes, L. Rebouta, J.G. Rocha, S. Lanceros-Méndez, G. Minas, Lab-on-a-chip with beta-poly(vinylidene fluoride) based acoustic microagitation, IEEE Trans. Biomed. Eng. 57 (2010) 1184-1190.

[54] A. del Campo, C. Greiner, SU-8: a photoresist for high-aspect-ratio and 3D submicron lithography, J. Micromech. Microeng. 17 (2007) R81-R95.

[55] S.B. Rodan, Y. Imai, M.A. Thiede, G. Wesolowski, D. Thompson, Z. Bar-Shavit, S. Shull, K. Mann, G.A. Rodan, Characterization of a human osteosarcoma cell line (Saos-2) with osteoblastic properties, Cancer Res. 47 (1987) 4961-4966.

[56] C. Pautke, M. Schieker, T. Tischer, A. Kolk, P. Neth, W. Mutschler, S. Milz, Characterization of osteosarcoma cell lines MG-63, Saos-2 and U-2 OS in comparison to human osteoblasts, Anticancer Res. 24 (2004) 3743-3748.

[57] M. Pilia, T. Guda, S.M. Shiels, M.R. Appleford, Influence of substrate curvature on osteoblast orientation and extracellular matrix deposition, J. Biol. Eng. 7 (2013) 23.

[58] C.A. Custódio, C.M. Alves, R.L. Reis, J.F. Mano, Immobilization of fibronectin in chitosan substrates improves cell adhesion and proliferation, J. Tissue Eng. Regen. Med. 4 (2010) 316-323.

[59] R.R. Costa, C.A. Custódio, F.J. Arias, J.C. Rodríguez-Cabello, J.F. Mano, Layer-by-layer assembly of chitosan and recombinant biopolymers into biomimetic coatings with multiple stimuli-responsive properties, Small 7 (2011) 2640-2649.

[60] N.M. Alves, C. Picart, J.F. Mano, Self assembling and crosslinking of polyelectrolyte multilayer films of chitosan and alginate studied by QCM and IR spectroscopy, Macromol. Biosci. 9 (2009) 776-785.

[61] G.V. Martins, J.F. Mano, N.M. Alves, Nanostructured self-assembled films containing chitosan fabricated at neutral pH, Carbohydr. Polym. 80 (2010) $571-574$.
[62] M.V. Voinova, M. Rodahl, M. Jonson, B. Kasemo, Viscoelastic acoustic response of layered polymer films at fluid-solid interfaces: continuum mechanics approach, Phys. Scripta 59 (1999) 391.

[63] J. Borges, S.G. Caridade, J.M. Silva, J.F. Mano, Unraveling the effect of the hydration level on the molecular mobility of nanolayered polymeric systems, Macromol. Rapid Commun. 36 (2015) 405-412.

[64] J. Borges, J.F. Mano, Molecular interactions driving the layer-by-layer assembly of multilayers, Chem. Rev. 114 (2014) 8883-8942.

[65] J.M. Silva, S.G. Caridade, R.R. Costa, N.M. Alves, T. Groth, C. Picart, R.L. Reis, J.F. Mano, PH-responsiveness of multilayered films and membranes made of polysaccharides, Langmuir 31 (2015) 11318-11328.

[66] M. Takami, Y. Suzuki, Hydrophobic blue pigment formation from phosphatidylgenipin, J. Nutr. Sci. Vitaminol. 40 (1994) 505-509.

[67] M.P. Sousa, F. Cleymand, J.F. Mano, Elastic chitosan/chondroitin sulfate multilayer membranes, Biomed. Mater. 11 (2016) 035008

[68] S. Hong, E. Ergezen, R. Lec, K.A. Barbee, Real-time analysis of cell-surface adhesive interactions using thickness shear mode resonator, Biomaterials 27 (2006) 5813-5820.

[69] M. Théry, Micropatterning as a tool to decipher cell morphogenesis and functions, J. Cell Sci. 123 (2010) 4201-4213.

[70] V. Karageorgiou, D. Kaplan, Porosity of 3D biomaterial scaffolds and osteogenesis, Biomaterials 26 (2005) 5474-5491.

[71] A. Graziano, R. d'Aquino, M.G. Cusella-De Angelis, G. Laino, A. Piattelli, M. Pacifici, A. De Rosa, G. Papaccio, Concave pit-containing scaffold surfaces improve stem cell-derived osteoblast performance and lead to significant bone tissue formation, PLoS One 2 (2007) e496.

[72] Y.-P. Lo, Y.-S. Liu, M.G. Rimando, J.H.-C. Ho, K.-H. Lin, O.K. Lee, Three-dimensional spherical spatial boundary conditions differentially regulate osteogenic differentiation of mesenchymal stromal cells, Sci. Rep. 6 (2016) 21253.

[73] S. Rausch, T. Das, J.R. Soiné, T.W. Hofmann, C.H. Boehm, U.S. Schwarz, H. Boehm, J.P. Spatz, Polarizing cytoskeletal tension to induce leader cell formation during collective cell migration, Biointerphases 8 (2013) 32 . 